\title{
A Brief Review on Health Implication of Skipping Breakfast with Emphasis on Weight Gain in Adults
}

\author{
Joseph-Shehu EM \\ Faculty of Health Science, Department of Nursing Science, National Open University of Nigeria, Nigeria \\ *Corresponding author: Joseph-Shehu EM, Department of Nursing Science, National Open University of Nigeria, Nigeria \\ Submission: 眥June 06, 2018; Published: 毕 December 11, 2018
}

\begin{abstract}
Regular eating of breakfast contributes to the nutritional health of an individual. Some people skipped breakfast because of the desire to lose weight. An individual that consumed breakfast regularly is more likely to exhibit high level of physical activity and cardio-respiratory fitness. This short review aims to examine health implication of skipping breakfast with emphasis on weight gain in adults. Skipping breakfast is a wrong step in weight loss management as several available literature links irregular consumptions of breakfast to weight gain. Skipping breakfast over an extended period has a negative effect on cardiometabolic risk profile. It increases the risk of developing metabolic syndrome that increases the risk of cardiovascular diseases and type 2 diabetes mellitus development. Consumption of breakfast regularly has been found to be an alternative means of weight management. Future research is needed to examine eating and time of breakfast as well as types of breakfast adults' in developing countries consumed in relation to their body mass index.
\end{abstract}

Keywords: Skipping breakfast; Overweight; Obesity; Cardiovascular diseases; Type 2 diabetes; Metabolic syndrome

\section{Introduction}

Breakfast is the first-morning meal, and many acknowledged it to be the most important meal of the day as taking breakfast is essential in promoting nutritional health [1]. Lippevelde et al. [2] described breakfast to be meal which can be in the form of food and/or drinks ate between $7 \mathrm{am}$ and 11am. Eating breakfast maintain healthy body mass index (BMI) in children and adolescent $[3,4]$. It also maintains weight-loss in adults [5]. Generally, people that eat breakfast regularly have better nutrient intakes, show better cognitive performance and less depressed [6]. Skipping breakfast leads to a decrease in academic and physical performance [7]. Apart from eating breakfast, the frequency of breakfast [8] and type of meal $[5,6,9]$ are also important in maintaining healthy nutritional lifestyle and weight. Adulthood is marked with several responsibilities that range from work, family and hurried lifestyle which many may respond to by skipping breakfast [5]. A study conducted among 1066 UK adults, showed that two-thirds of the study population were habitual breakfast eaters while 1 in 16 never had breakfast [6]. Children, adolescents and adults skipped breakfast because there is a misconception that skipping breakfast could help to control weight [10]. The first step many made when they desire to lose weight is to skipped breakfast [11]. Females are more likely to skipped breakfast than males and taste, health concerns and appetite influences individual breakfast behaviour [6]. Literature reveals that skipping breakfast is a risk for overweight and obesity [6,11-13]. Irregular or skipping breakfast is linked to weight gain, type 2 diabetes and other adverse health outcomes [10]. There is an increased risk of coronary heart disease
(CHD) among men who skipped breakfast [12]. Regular breakfast eaters are more likely to exhibit a high level of physical activity, and they reported high level of cardio-respiratory fitness [6].

Consumption of breakfast that are low glycaemic index and, bran based enhances cognitive performance compared to breakfast cereals with a high glycaemic index [6]. A study reported lower mean values for total cholesterol, waist circumference, blood pressure, blood glucose, BMI, and lower prevalence of metabolic syndrome among adults that frequently eat typical Italian breakfast [5]. Women reported to be less hungry, fuller, happier, more relaxed, satisfied with their body image and weight after consuming a cereal-based breakfast compared to a muffin, despite similar calories being provided by both breakfasts [6]. High carbohydrate intake for breakfast and reduces calories for dinner have a longterm protective effect against the development of metabolic syndrome as is a useful alternative for management of overweight and obesity [13]. Furthermore, consumption of ready-to-eat cereal breakfast was linked with an improved cardiometabolic risk profile compared to other types of breakfast [10]. Skipping breakfast is associated with impair serum lipids and postprandial insulin sensitivity [12] while regular breakfast is associated with a lower risk for development of type 2 diabetes (T2D) [10]. Obesity is a common risk factor to development of hypertension, dyslipidemia, T2D [14,15] and cancer [16]. Gradual weight gain resulted from skipping breakfast [10] will cumulate to overweight which if not well managed, progresses to obesity that is assumed to contribute to the burden of cardiovascular diseases [14]. 
Overweight and obesity are of public health concerns as its recognised to be risk factors for many chronic diseases and described as a global pandemic due to his rising prevalence in many countries. Overweight is defined as body mass index (BMI) greater than or equal to 25 and lower than 30 while obesity is BMI greater than 30 [17]. It is caused by a long-term positive energy balance occurring when the energy intake outweighs the energy expenditure [2]. Overweight and obesity increased the rate of developing cardiovascular diseases (CVDs), type 2 diabetes [16,18,19], metabolic syndrome [5], chronic back pain and osteoarthritis [20]. It increases the burden of diseases globally [14], and the universal rising in overweight and obesity may lead to future declines in life expectancy [17]. Metabolic syndrome is a common underlying pathophysiological disturbance [13]; it increases CVDs risk by $20 \%$ and the risk for type 2 diabetes mellitus by $50 \%$ [5]. Skipping breakfast has 3.4-fold higher risk of developing Mets compared with less than three hours dinner before bedtime [7]. Skipping breakfast over a long period has a negative effect on cardiometabolic risk profile [5]. It increased the risk of overweight and increased postprandial insulin resistance as well as hyperinsulinemia in response to foods consumed at the next meal [10]. Thomas et al. and Cahill et al. reported that skipping breakfast results to overweight, obesity, dyslipidaemia, increased blood pressure, insulin sensitivity, diabetes mellitus, increased risk of coronary heart diseases [12,21]. Yoko et al reported on a study conducted in the United States that people skipped breakfast became obese at a rate five times higher than people who ate breakfast [7]. Overweight and obesity are associated with increased risk for development of diabetes and hypertension [20,22]. There are limited studies that reported on type(s) of meal(s) consumed by African and time for breakfast in relation to BMI and waist-hip ratio. Skipping breakfast causes a shift in the phase of expression of the clock gene, resulting in a nocturnal lifestyle pattern, which may be associated with obesity [7]. In conclusion, regular eating of breakfast is important in prevention of overweight and obesity which subsequently control and prevent all its associated health problems. The prevalence of metabolic syndrome like cardiovascular diseases and T2D in developing countries is on the increased $[20,23,24]$. Overweight and obesity were estimated to cause 3.4 million deaths, $3.9 \%$ of years of life lost and $3.8 \%$ of disability-adjusted life years (DALYs) globally [17]. Therefore, this review calls for need for future research on consumption and time of breakfast as well as types of breakfast consumed by African in relation to adults' body mass index (BMI).

\section{References}

1. Affinita A, Catalani L, Cecchetto G, Lorenzo G, Dilillo D, et al. (2013) Breakfast: A multidisciplinary approach. Italian Journal of Pediatrics 39(1): 44.

2. Lippevelde VW, Velde SJ, Verloigne M, Stralen MM, Bourdeaudhuij I, et al. (2013) Associations between family-related factors, breakfast consumption and BMI among 10-to 12-year-old European children: The cross-sectional energy-study. PLoS One 8(11): e79550.

3. Adolphus K, Lawton CL, Dye L (2013) The effects of breakfast on behaviour and academic performance in children and adolescents. Front Hum Neurosci 7: 425.
4. Liu J, Hwang WT, Dickerman B, Compher C (2013) Regular breakfast consumption is associated with increased IQ in kindergarten children. Early Hum Dev 89(4): 257-262.

5. Deshmukh TP, Nicklas TA, Radcliffe JD, Oneil CE, Liu Y (2013) The relationship of breakfast skipping, and type of breakfast consumed with overweight/obesity, abdominal obesity, other cardiometabolic risk factors and the metabolic syndrome in young adults. The National Health and Nutrition Examination Survey (NHANES): 1999-2006. Public Health Nutr 16(11): 2073-2082.

6. Reeves S, Huber J, Halsey LG, Villegas MM, Elgumati J, et al. (2015) A cross-over experiment to investigate possible mechanisms for lower BMIs in people who habitually eat breakfast. Eur J Clin Nutr 69(5): 632637.

7. Watanabe Y, Saito I, Henmi I, Yoshimura K, Maruyama K, et al. (2014) Skipping breakfast is correlated with obesity. J Rural Med 9(2): 51-58.

8. Shafiee G, Kelishadi R, Qorbani M, Motlagh ME, Taheri M, et al. (2013) Association of breakfast intake with cardiometabolic risk factors. J Pediatr (Rio J) 89(6): 575-582.

9. Barr SI, Difrancesco L, Fulgoni VL (2013) Consumption of breakfast and the type of breakfast consumed are positively associated with nutrient intakes and adequacy of Canadian adults. The Journal of Nutrition 143(1): 86-92.

10. Mekary RA, Giovannucci E, Cahill L, Willett WC, Dam RM, et al. (2013) Eating patterns and type 2 diabetes risk in older women: breakfast consumption and eating frequency. J Nutr 98(2): 436-443.

11. Levitsky DA, Pacanowski CR (2013) Effect of skipping breakfast on subsequent energy intake. Physiol Behav 119: 9-16.

12. Cahill LE, Chiuve SE, Mekary RA, Jensen MK, Flint AJ, et al. (2013) Prospective study of breakfast eating and incident coronary heart disease in a cohort of male US Health Professionals. Circulation 128(4): 337-343.

13. Jakubowicz D, Barnea M, Wainstein J, Froy O (2013) High caloric intake at breakfast vs dinner differentially influences weight loss of overweight and obese women. Obesity 21(12): 2504-2512.

14. Yatsuya H, Li Y, Hilawe EH, Ota A, Wang C, et al. (2014) Global trend in overweight and obesity and its association with cardiovascular disease incidence. Circ J 78(12): 2807-2818.

15. Ali MK, Jaacks LM, Kowalski AJ, Siegel KR, Ezzati M (2015) Noncommunicable diseases: three decades of global data show a mixture of increases and decreases in mortality rates. Health Aff (Millwood) 34(9): 1444-1455.

16. Huxley R, Mendis S, Zheleznyakov E, Reddy S, Chan J (2010) Body mass index, waist circumference and waist: hip ratio as predictors of cardiovascular risk-a review of the literature. Eur J Clin Nutr 64(1): 16-22.

17. Ng M, Fleming T, Robinson M, Thomson B, Graetz N, et al. (2014) Global, regional, and national prevalence of overweight and obesity in children and adults during 1980-2013: A systematic analysis for the global burden of disease study 2013. lancet 384(9945): 766-781.

18. Ferreira JRD, Aleluia MM, Figueiredo CVB, Vieira LCDL, Santiago RP, et al. (2017) Evaluation of cardiometabolic parameters among obese women using oral contraceptives. Frontiers in Endocrinology 8: 256.

19. http://www.who.int/mediacentre/factsheets/fs355/en/

20. Msyamboza KP, Mvula CJ, Kathyola D (2014) Prevalence and correlates of diabetes mellitus in Malawi: population-based national NCD steps survey. BMC Endocr Disord 14(1): 41.

21. Thomas EA, Higgins J, Bessesen DH, Mcnair B, Cornier MA (2015) Usual breakfast eating habits affect response to breakfast skipping in overweight women. Obesity (Silver Spring) 23(4): 750-759.

22. Msyamboza KP, Kathyola D, Dzowela T (2013) Anthropometric measurements and prevalence of underweight, overweight and obesity in 
adult Malawians: nationwide population based NCD steps survey. Pan Afr Med J 15(1): 108

23. Isara AR, Okundia PO (2015) The burden of hypertension and diabetes mellitus in rural communities in southern Nigeria. Pan Afr Med J 20: 103.
24. http://www.who.int/mediacentre/factsheets/fs355/en/ (c) (i) Creative Commons Attribution 4.0 International License

For possible submissions Click Here
Submit Article
EPMR Examines in
Physical Medicin
\& Rehabilitition



Examines in Physical Medicine and Rehabilitation: Open Access

\section{Benefits of Publishing with us}

- High-level peer review and editorial services

- Freely accessible online immediately upon publication

- Authors retain the copyright to their work

- Licensing it under a Creative Commons license

- Visibility through different online platforms 